\title{
Compensating changes in the penetration depth of pulse limited radar altimetry over the Greenland ice sheet
}

\author{
Thomas Slater, Andrew Shepherd, Malcolm McMillan, Thomas W. K. Armitage, Inès Otosaka, and Robert J. \\ Arthern
}

\begin{abstract}
Changes in firn properties affect the shape of pulselimited radar altimeter echoes acquired over the polar ice sheets. We apply a waveform deconvolution model to CryoSat-2 low-resolution mode echoes to determine the depth-distribution of radar backscattering across the Greenland ice sheet. The deconvolution allows us to calculate the relative contributions of surface and volume scattering, and the effective penetration depth of the radar echoes into the snowpack. The most prominent signal is that associated with the extreme surface melting of summer 2012, which resulted in a shift of the dominant radar scattering horizon towards the snow surface in the accumulation zone. At locations above $2000 \mathrm{~m}$, the average penetration depth in July 2012 (prior to the melt event) was $3.79 \pm 1.12 \mathrm{~m}$. Following the melt event, there was an abrupt reduction in the average penetration depth across the same region to $1.45 \pm 0.94 \mathbf{~ m}$. The average penetration depth then gradually increased to 3.28 $\pm 1.13 \mathrm{~m}$ by the end of 2017 , as fresh snow accumulated on the ice sheet surface. Although the variation in penetration is evident in surface height estimates derived from the CryoSat2 echoes, the magnitude of the effect is reduced by waveform retracking. Using airborne laser altimeter data recorded over the same time period, we show that the penetration variation can be compensated effectively by incorporating the deconvolution penetration depth into the surface height retrieval.
\end{abstract} try

Index Terms-CryoSat-2, Greenland, ice sheets, radar altime-

\section{INTRODUCTION}

$\mathbf{M}$ EASUREMENTS of surface elevation change from satellite radar altimeters have transformed our understanding of the Greenland ice sheet, resolving detailed patterns of thinning across dynamic marine-terminating glaciers and in the ice sheet margins, where surface melting occurs each summer [1]-[7]. Satellite radar altimeters transmit a microwave pulse at nadir, and record backscattered power as a function of time delay (the echo). Over ice, the shape of altimeter echoes is complicated by (1) ice sheet topography (surface scattering), and (2) the $\mathrm{Ku}$ band radar penetrating several metres beyond the snow surface (volume scattering) [8]-[12]. The depth of radar penetration is dependent on the physical

T. Slater, A. Shepherd and I. Otosaka are with the Centre for Polar Observation and Modelling, School of Earth and Environment, University of Leeds, Leeds, LS2 9JT, United Kingdom (e-mail: py10ts@leeds.ac.uk).

M. McMillan is with the Lancaster Environment Centre/Data Science Institute, Lancaster University, Lancaster, LA1 4YW, UK.

T. W. K. Armitage is with the Jet Propulsion Laboratory, California Institute of Technology, Pasadena, California, USA.

R. J. Arthern is with the British Antarctic Survey, High Cross, Madingley Rd, Cambridge CB3 OET, UK. properties of the ice sheet surface and near-surface snowpack (e.g. grain size, density, liquid water content) [13], which exhibit both spatial and seasonal variability [14]. The precise height of the ice sheet surface is estimated from altimeter echoes through retracking algorithms, designed to be less sensitive to fluctuations in penetration by focussing on the surface scattering contribution to the echo leading edge [3], [15].

In July 2012 an unprecedented proportion (98.6\%) of the Greenland ice sheet experienced surface melting as increased transport of warm air from the south created anomalously high temperatures [16], [17]. This event was clearly visible in passive and active microwave imagery [16], [18], [19], extending inland to high altitude regions (approximately $>$ 2800 m.a.s.l.) which had not seen melting during the satellite era [20]. Meltwater percolated and re-froze in a layer near to the snow surface [16], altering the physical properties of the firn layer within which radar altimeter echoes are scattered. Across the ice sheet interior, an apparent $89 \pm 49$ $\mathrm{cm}$ increase in surface elevation was recorded in uncorrected CryoSat-2 satellite radar altimeter elevation data after the melt event [21]. A range of approaches have been employed to mitigate this effect, including applying (1) threshold retrackers [3], [5], which are less sensitive to variations in volume scattering, (2) a step offset to the affected elevation time series [4] and (3) a correction to retracked heights based upon correlated fluctuations between elevation change and several echo parameters including the leading edge width, trailing edge slope and backscatter coefficient [6], [7]. Here, we employ a waveform deconvolution model to CryoSat-2 data to retrieve the depth-distribution of radar scattering across the interior of the Greenland ice sheet, and to compensate surface height retrievals for the effects of temporal variations in firn properties.

\section{DATA AND METHODS}

\section{A. Penetration Depth}

CryoSat-2, launched in 2010, was designed to overcome challenges faced by previous satellite radar altimeters over Earths polar regions. Equipped with a novel synthetic aperture radar altimeter and interferometer providing high spatial resolution measurements in areas of steep terrain, CryoSat-2 observes to latitudes of $\pm 88^{\circ}$, with a long-period, drifting orbit (369-day repeat period with a 30-day subcycle) which 

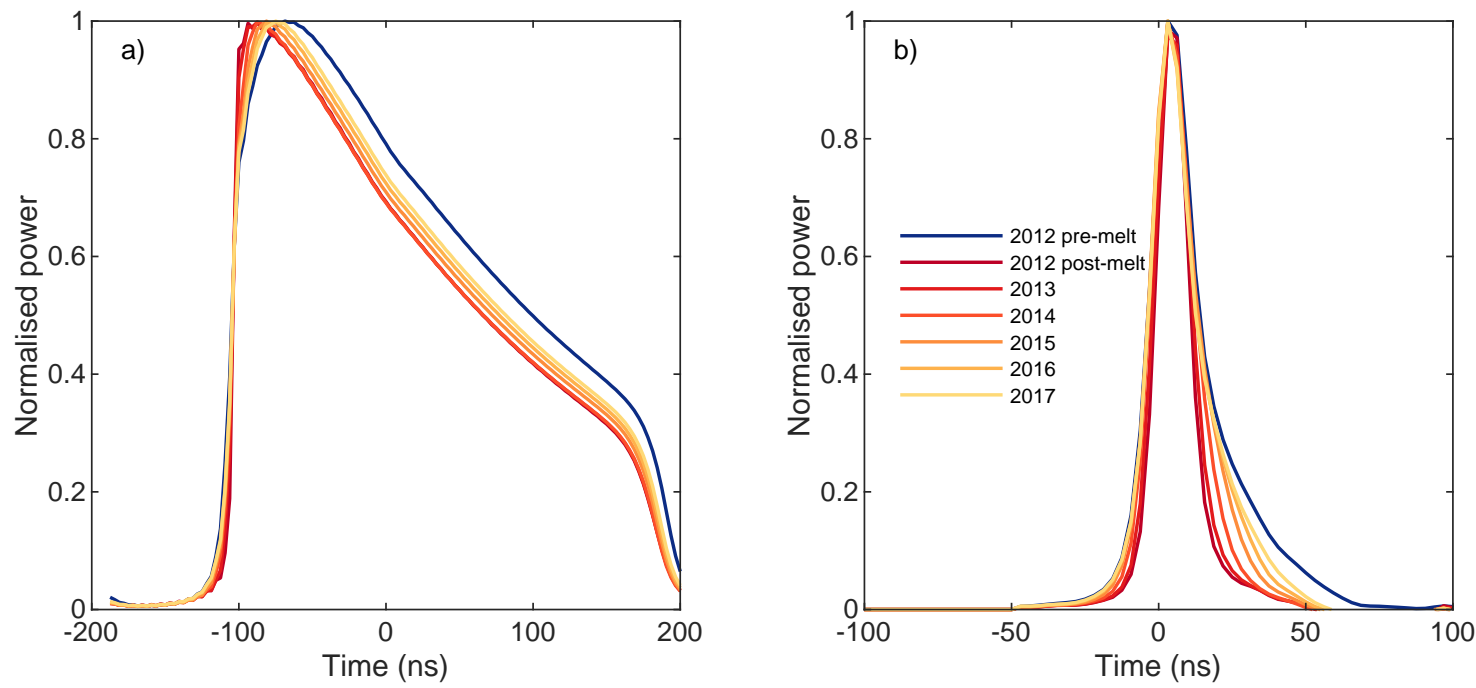

Fig. 1. Average of (a) CryoSat-2 low-resolution mode echoes and (b) their respective deconvolutions acquired in areas exceeding $2000 \mathrm{~m}$ in elevation before (January-June) and after (August-December) the melt event of July 2012, and during the subsequent years (2013 to 2017). Plotted waveforms and deconvolutions are normalized to peak power of unity.

affords a high density of orbit cross-overs at the poles [11]. Across the interior of the Greenland ice sheet, CryoSat-2 acquires measurements in low-resolution mode (LRM), where it operates as a traditional pulse-limited altimeter illuminating a ground footprint of $1.5 \mathrm{~km}$ diameter [22]. Previous studies have investigated the effects of variable surface and volume scattering on altimeter echoes acquired over ice sheets through fitting a theoretical model to both averaged [9], [23] and individual altimeter echoes [24]. Here, we investigate spatial and temporal variations in the degree of radar penetration into the Greenland ice sheet, using CryoSat-2 Level $1 \mathrm{~b}$ baselineC data acquired between January 2011 and December 2017 and a numerical deconvolution technique [10], [25] designed to separate the effects of scattering from the surface and from greater depth within the snowpack. This model assumes that the effects of large scale surface slope and footprintscale topographic undulations upon the waveform shape are negligible, and is therefore only appropriate in areas of flat terrain.

First, we describe CryoSat- 2 echoes as a convolution of three functions [8], [26]:

$$
P_{R}(t)=P_{T}(t) * P_{F S}(t) * P_{D}(t)
$$

where $P_{R}(t)$ is the pulse received at the antenna as a function of time, $t, P_{T}(t)$ is the transmitted pulse shape, $P_{F S}(t)$ is the normalised flat surface impulse response and $P_{D}(t)$ is the distribution of backscattered power with depth and surface roughness height. $P_{F S}(t)$ represents the echo that would be recovered from an ideal flat surface if a delta function were transmitted, if no penetration occurred and if the flat surface had a backscatter coefficient equal to unity. In this way,
$P_{D}(t)$ contains both the surface and volume backscattering cross sections. Over ice sheets, $P_{D}(t)$ contains all scattering contributions from both the ice sheet surface and due to penetration of the radar pulse into the snowpack.

The Fourier transform of a convolution of time-dependent functions is equal to the product of their spectra in the frequency domain, $\omega$. Utilising this property, (1) can be rewritten as:

$$
\begin{array}{r}
P_{R}(t)=P_{T}(t) * P_{F S}(t) * P_{D}(t) \leftrightarrow \\
P_{T}(\omega) P_{F S}(\omega) P_{D}(\omega)=P_{R}(\omega)
\end{array}
$$

where $\leftrightarrow$ denotes the Fourier transform operation. By performing the Fourier transform, we are able to isolate the distribution of scattering with depth and surface roughness height, $P_{D}(t)$, by removing convolved scattering contributions outside the point of closest approach within a given radar footprint in the frequency domain. Before deconvolving, we downsample the CryoSat-2 echoes from $20 \mathrm{~Hz}$ to $1 \mathrm{~Hz}$ in order to reduce the effects of speckle noise, and because individual echoes are more distorted by topography within the radar footprint than their average. Rearranging and rewriting (2) gives:

$$
P_{D}(t) \leftrightarrow \frac{P_{R}(\omega)}{P_{T}(\omega) \overline{P_{F S}(\omega)}} \Pi(\omega)
$$

where $P_{T}(\omega) \overline{P_{F S}(\omega)}$ is the product of the transmitted and the mean flat surface impulse response spectra, and $\Pi(\omega)$ is a Gaussian low-pass smoothing filter with a standard deviation of 40 frequency bins. As an empirical approximation for $P_{T}(\omega) \overline{P_{F S}(\omega)}$, we assume that the average impulse response of an a flat ice sheet is equal to that of a uniformly rough 
ocean surface (i.e. $P_{D}(t)$ approaches that of a Dirac delta function, $\delta(t)$ ). To estimate this response, we use the mean of a set of CryoSat-2 LRM echoes acquired over a region of the Mediterranean Sea where the significant wave height is less than $0.1 \mathrm{~m}$ and the impact of surface roughness on the waveform is minimised.

In order to obtain information about the scattering properties of the illuminated snowpack, we fit an analytical function [10] to the resulting deconvolutions $(4), P_{D}(t)$ through a nonlinear least-squares regression (using the Levenberg-Marquardt algorithm, [27]) such that:

$$
\begin{array}{r}
P_{D}\left(t ; \sigma_{\text {surf }}^{0}, \sigma_{\text {vol }}^{0}, k_{e}, \gamma, \bar{t}\right)=\frac{\sigma_{\text {surf }}^{0}}{\gamma \sqrt{\pi}} \exp \left(-\frac{(t-\bar{t})^{2}}{\gamma^{2}}\right) \\
+\frac{\sigma_{\text {vol }}^{0} c_{i c e} k_{e}}{2} \cdot \exp \left(\frac{\gamma^{2} c_{i c e}^{2} k_{e}^{2}}{4}-c_{i c e} k_{e}(t-\bar{t})\right) \\
\cdot\left[1+\operatorname{erf}\left(\frac{(t-\bar{t})}{\gamma}-\frac{\gamma c_{i c e} k_{e}}{2}\right)\right]
\end{array}
$$

where $\sigma_{\text {surf }}^{0}$ is the surface backscatter cross section, $\sigma_{v o l}^{0}$ is the depth-integrated volume backscatter, $k_{e}$ is the extinction coefficient, $\gamma$ is the leading edge width, and $\bar{t}$ is the leading edge time delay (e.g. Fig. 1). The leading edge width and delay time refer to those that apply after the ocean echo has been removed, and following the application of the smoothing filter. The influence of the significant wave height and smoothing filter on the modelled leading edge width are small relative to the effects of surface roughness and the depth of radar penetration. We use $c_{i c e}=2.2 \times 10^{8} \mathrm{~m} / \mathrm{s}$, which is a common value for the speed of light in densities typical of the upper snowpack [13]. In (4), echoes are modelled as the sum of contributions due to scattering from the snow surface (a Gaussian peak) and from the subsurface volume (an exponentially decaying tail). $\sigma_{\text {surf }}^{0}$ and $\sigma_{v o l}^{0}$, the integrals of the surface and volume scattering terms, describe their relative strength, while $k_{e}$ denotes the rate (in units of $\mathrm{m}^{-1}$ ) that the radar signal is attenuated as it travels into the snowpack. We note that the units of $\sigma_{\text {surf }}^{0}$ and $\sigma_{v o l}^{0}$ are dependent upon the CryoSat-2 ice and ocean waveforms being normalised during the deconvolution procedure, in order to account for the differing strength of their respective returns. Because of this, we recover backscatter coefficients relative to a reference backscatter (that of the ocean echo used in the deconvolution). Together, these three parameters describe the scattering behaviour of the snowpack and allow estimation of the radar penetration depth, defined as the inverse of the extinction coefficient [10].

We estimate $\sigma_{\text {surf }}^{0}, \sigma_{\text {vol }}^{0}$, and $k_{e}$ from deconvolved CryoSat2 L1b LRM echoes acquired across the interior of the Greenland ice sheet between January 2011 and December 2017. We limit our analyses to the region of the ice sheet interior above the $2000 \mathrm{~m}$ contour, in order to provide a continuous, $\sim 710,000 \mathrm{~km}^{2}$ area in which the ice sheet surface slopes are low (approximately 0.1 on average), which covers the entirety of the dry snow zone where the scattering horizon was reset in 2012, and which corresponds to $92 \%$ of the area sampled in LRM. Solutions where the scattering model fails to converge after 20 iterations (through minimising the chi-squared error of the fit), and that yield unrealistic penetration depths of more than $10 \mathrm{~m}$ are excluded. To investigate spatial and temporal variations, we compute the mean values of each of the three scattering parameters within $25 \times 25 \mathrm{~km}$ grid cells and within discrete time intervals (e.g. Fig. 2). To track temporal changes in penetration depth we then average the data in monthly time intervals (e.g. Fig. 3a).

\section{B. Elevation Change}

A variety of retracking routines have been applied to satellite altimeter waveforms to improve the accuracy, precision, and stability of ice sheet surface height retrieval [3], [15], [28]. To assess the impact of the Greenland ice sheet surface properties, we compare temporal variations in the radar penetration depth before and after significant melting events to changing surface heights estimated using conventional waveform retracking algorithms. To compute the latter, we use measurements of ice sheet surface elevation determined using two waveform retrackers available in the Level $2 \mathrm{i}$ baseline-C product: (1) a model based algorithm, CFI [29], historically available in the baseline-B product and known to be sensitive to fluctuations in the scattering horizon [5], and (2) a threshold offset center of gravity (TCOG) retracking algorithm, which selects a threshold power of $30 \%$ of the OCOG amplitude. With these algorithms we analyse the effects of variable radar penetration on the two main classes of retracker most commonly used in the literature: physically-based (CFI), and empirically-based (TCOG). While other empirical threshold retrackers have been used in previous studies, and provide less weight to later delay times as they focus only on the leading edge of the waveform (e.g. [3]), we contrast the echo deconvolution to those included in the ESA Level 2i product. Time-series of ice sheet surface elevation change are then generated from these measurements using a model fit [4], [30] to separate spatial and temporal fluctuations within $5 \times 5 \mathrm{~km}$ grid cells:

$z(x, t, y, h)=\bar{z}+a_{0} x+a_{1} y+a_{2} x^{2}+a_{3} y^{2}+a_{4} x y+a_{5} h+a_{6} t$

where we model the elevation $(z)$ as a function of the local surface terrain $(x, y)$, satellite heading $(h$, which equals 0 or 1 whether measurement was acquired on an ascending or descending pass, respectively) and time $(t)$. We solve for the individual model coefficients using an iterative least-squares fit to minimise the impact of outliers, and discard any unrealistic estimates from poorly constrained solutions based on a set of statistical thresholds which include: a minimum of 40 data points, a time series length of at least 2 years, a maximum root mean squared difference of elevation residuals from the model of $12 \mathrm{~m}$, a maximum elevation rate magnitude of $10 \mathrm{~m} / \mathrm{yr}$, and a maximum surface slope of $5^{\circ}$. The resulting time-series are then averaged within $25 \times 25 \mathrm{~km}$ grid cells and across monthly intervals to allow comparison with the estimates of penetration depth obtained from the deconvolution procedure at the same location (e.g. Fig. 3b). A resolution of $25 \mathrm{~km}$ has been selected as a balance between the spatial resolution 

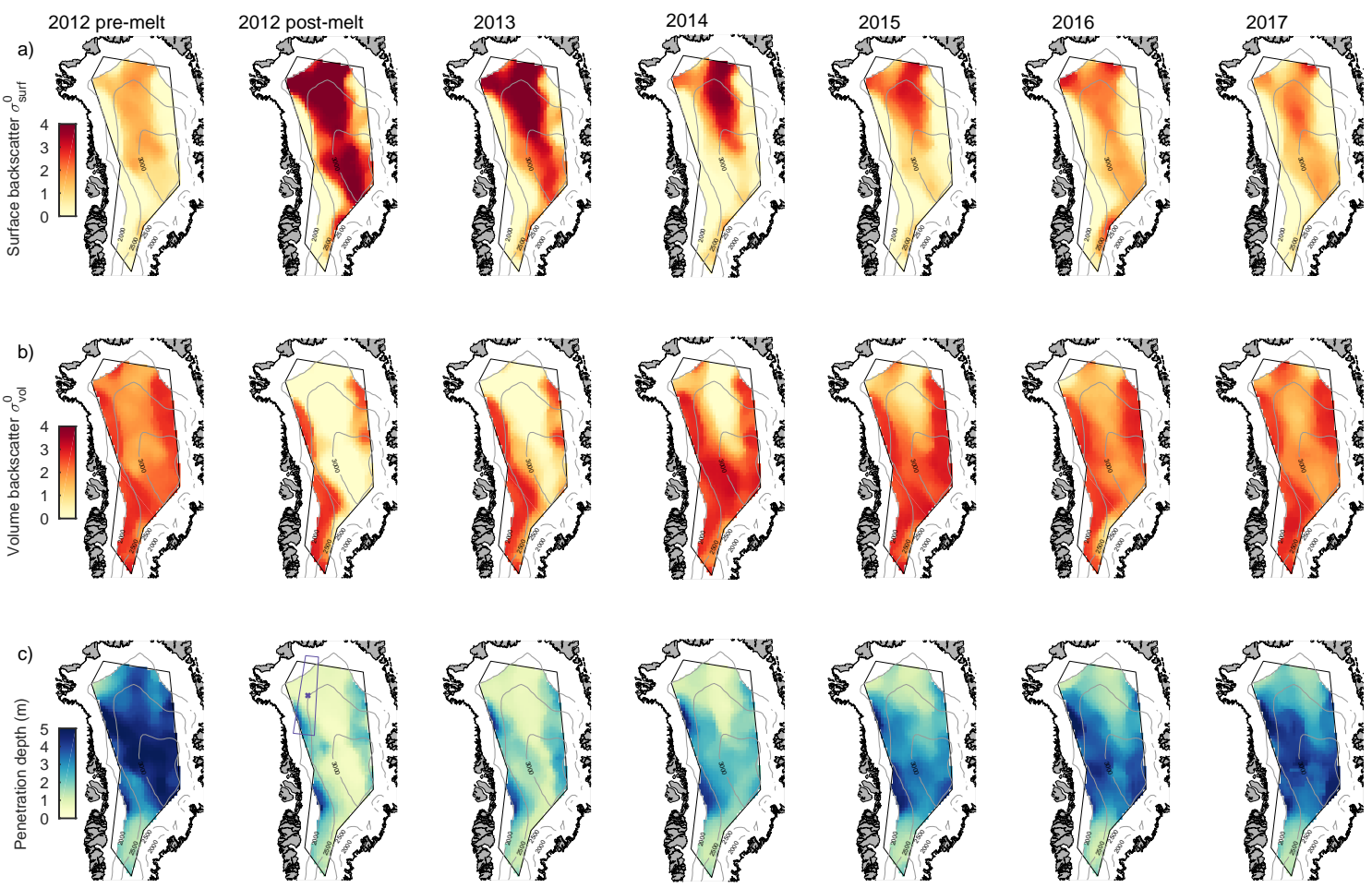

Fig. 2. Pre- and post-melt event and yearly averages of a) surface backscatter coefficient, b) volume backscatter coefficient and c) penetration depth during the period 2012-2017. In each plot, the black line represents the boundary between LRM and SARIn mode acquisitions, and grey lines represent elevation contours of 2000, 2500 and $3000 \mathrm{~m}$. Shading represents extent of the ice sheet (white) and surrounding land (grey). Also shown (purple, c) 2012 post-melt) is the location of the North Greenland Eemian Ice Drilling Project site and surrounding area used for comparison to Nilsson et al. [21].

and the number of measurements averaged to reduce noise in our monthly penetration depth time series. Within any given time series, we quantify the uncertainty at each epoch by computing the regional average of the standard error of height change measurements within all contributing pixels. We assume this component is temporally uncorrelated, therefore at any given epoch we sum all preceding uncertainties in quadrature. To obtain the error on the overall elevation change, we combine this uncertainty with the standard error of the rate of surface elevation change in quadrature, in order to account for systematic errors which may affect the trend.

Time-series of ice sheet elevation change computed using conventionally retracked waveforms have exhibited seasonal cycles [31]-[33] and episodic shifts [21] that track changes in the echo properties, which have been interpreted as owing to changes in the surface scattering [4]-[6]. To account for these, we first apply a correction based upon correlations between changes in elevation and backscattered power [4], [32] (e.g. Fig. 3b). As an alternative approach, we also explore the use of the penetration depth determined from our deconvolution method as the basis for a volume scattering correction (e.g. Fig. 3b). We do not, however, apply the penetration depth as an explicit correction to the L2 data, because the conventional waveform retracking routines have been designed in part to minimize the effects of volume scattering, and because the scattering correction may not be entirely due to fluctuations in penetration. Instead, we develop a surface scattering correction based on the ratio between changes in penetration depth and elevation, and we then apply the correction to retracked heights at each point in our elevation time series such that:

$$
d H_{\text {corrected }}=d H-\frac{d H}{d k_{e}^{-1}} \cdot d k_{e}^{-1}
$$

where $d H$ is the elevation change at each epoch, $k_{e}^{-1}$ is the radar penetration depth, and $\frac{d H}{d k_{e}^{-1}}$ is the correlation gradient between changes in elevation and penetration depth.

To complement the LRM data, which survey the ice sheet interior, we also compute time-series of surface elevation change from CryoSat-2 measurements acquired in synthetic aperture radar interferometry (SARIn) mode around the ice sheet margin. In this mode, CryoSat-2 uses two receive antennae to determine the location of the point of closest approach in the across-track plane through interferometry, with an alongtrack ground resolution of approximately $400 \mathrm{~m}$ [25]. SARIn elevation estimates are determined using the ESA Level 2 SARIn retracker, which fits an analytical model to each SAR waveform [11], [29]. We then compute elevation trends using the same model fit [4], [30] applied to measurements collected within $5 \mathrm{~km}$ grid cells, only we preserve the trends at this resolution to better describe the complex topography of the ice sheet margins. We do not attempt to deconvolve the SARIn echoes as the terrain is not flat. Although this prevents us from 

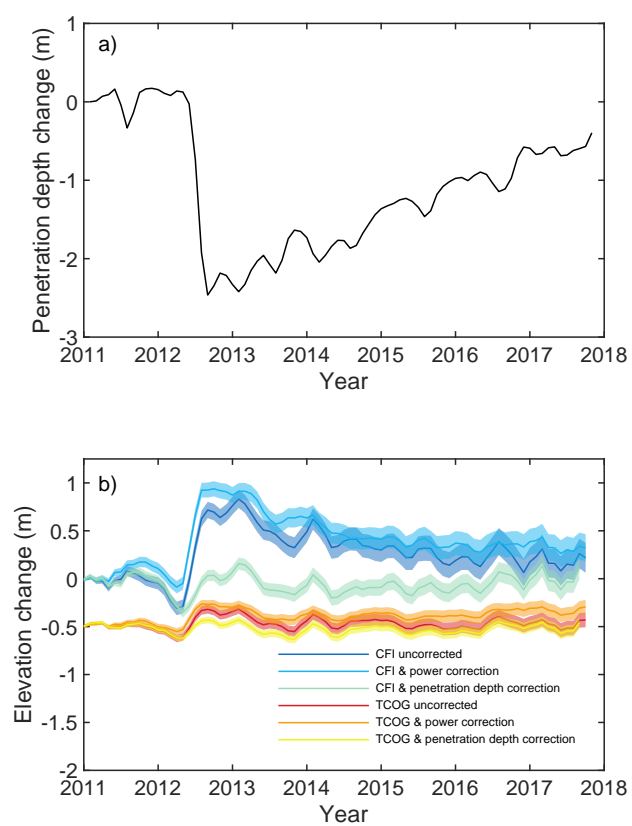

Fig. 3. Monthly evolution of the change in a) penetration depth and b) elevation in the interior of the Greenland ice sheet (> 2000 m.a.s.1.), 20112017. Time series of elevation change are calculated using the CFI (blue) and TCOG (red) retracking algorithms, both before and after applying corrections for correlated fluctuations in backscattered power and penetration depth. For visualisation purposes, an offset of $50 \mathrm{~cm}$ has been applied to the TCOG time series.

estimating the penetration depth, we instead adjust the time series of elevation change to account for temporal variations in the degree of radar penetration using a correction based upon correlated fluctuations in elevation and backscattered power [4], [32].

Elevation trends in empty grid cells at elevations below 2000 m.a.s.l. are filled using an empirical model based upon latitude, elevation and velocity change, all of which affect surface elevation change through temperature-related processes or ice flow [4]. We model the observed elevation trend as function of latitude $(l)$, elevation $(z)$ and change in velocity $(\Delta v)$ :

$$
\frac{d z}{d t}=a l+b z+c \Delta v+d
$$

which we then use to estimate trends in unobserved grid cells. The change in velocity was computed by differencing velocities recorded in 2008-2009 and 2000-2001 [34], [35]. Where no velocity data is available, we use a model based on latitude and elevation only. Based upon the root mean squared difference of the residuals to the model fit, we estimate an average uncertainty in unobserved grid cells of $0.4 \mathrm{~m} / \mathrm{yr}$.

\section{RESUlTS AND DISCUSSION}

To examine the effect of the 2012 melt event on elevation trends derived over varying timescales, we process data over two time periods: (1) 2011-2014, similar to the temporal extent of previous studies affected by melting [4]-[6], and (2) 2011-2017, which we expect to be less influenced by the 2012 melt event, given the longer duration of the record. We compare rates of elevation change determined from the LRM and SARIn data to estimates derived from Operation IceBridge repeat airborne laser altimetry [36]. For our shorter 2011-2014 period, we remove any IceBridge elevation rates which do not span the melt event, any which are outside the dry snow zone, and any for which the repeat period is less than 2 years. In total, this accounts for $34 \%(821,000)$ of all IceBridge measurements acquired between 2011 and 2014. For the 2011-2017 period, we utilise all available data to maximize the number of available comparisons. For both time periods, we bin the IceBridge measurements at a resolution of $25 \mathrm{~km}$ and $5 \mathrm{~km}$ within the LRM and SARIn areas, respectively, and remove any grid cells sampled by less than 10 IceBridge measurements or where the standard deviation of laser altimetry elevation rates is greater than $2 \mathrm{~m} / \mathrm{yr}$. These filtering steps removed $12 \%$ and $15 \%$ of grid cells between 2011 and 2014, and $5 \%$ and $15 \%$ of grid cells between 2011 and 2017 in the LRM and SARIn zones, respectively. Overall, we compare rates of elevation change in 135 and 3375 grid cells between 2011 and 2014, and 585 and 8788 grid cells between 2011 and 2017 in the LRM and SARIn zones, respectively.

\section{A. Penetration Depth}

Deconvolutions of CryoSat-2 LRM echoes acquired before and after the 2012 melt event (Fig. 1) demonstrate a clear shift from a situation dominated by volume scattering (power within the decaying tail, delay times greater than zero), to scattering from near to the snow surface (specular peak, increased backscatter at delay times near zero). Variations in the shape of the original CryoSat-2 LRM echoes (Fig. 1) are also visible, but disentangling the effects of surface contributions beyond the point of closest approach (POCA) and radar penetration is more difficult, as both redistribute backscattered power to later delay times in the leading edge [10]. By removing scattering contributions outside the POCA within a given radar footprint through the deconvolution procedure, the distribution of scattering with depth and surface roughness can be more clearly observed. In the years 2013-2017, the deconvolved echoes show a continuous increase in volume backscatter, returning to the shape observed before the melt event (Fig. 1b).

Across the ice sheet interior as a whole, there is a two-fold increase in the proportion of backscattered power returning from the ice sheet surface $\left(\sigma_{\text {surf }}^{0}\right)$ after the melt event, on average (Fig. 2) . In regions above $2000 \mathrm{~m}$ in altitude, we estimate that the radar penetration depth decreased by approximately $2.34 \pm 1.41 \mathrm{~m}$ on average, between the months before (January-June) and after (August-December) the formation of the new scattering horizon in July 2012 (Fig. 2) (penetration depth uncertainties are defined to be one standard deviation of the spatial variability). In higher altitude areas above 2800 m.a.s.l. which experienced melting for the first time in the satellite era, we estimate an even greater reduction in $\mathrm{Ku}$ band 
radar penetration depth of $3.21 \pm 1.16 \mathrm{~m}$. At lower elevation regions towards the south of the LRM zone $(<2500$ m.a.s.l.), there is little change in the scattering horizon following the melt event (Fig. 2). Using definitions of ice melt zones used in McMillan et al. [4] and Leeson et al. [37], we find that this area is within the percolation zone which typically experiences melt each summer [18]. In the percolation zone, there is no clear evidence of a coherent change in penetration depth following the 2012 melt event, with an estimated change of $0.25 \pm 0.61$ $\mathrm{m}$. Excluding the percolation zone, the decrease in penetration depth in the dry snow zone following the 2012 summer melt event is $2.64 \pm 1.16 \mathrm{~m}$ on average.

The effect of the 2012 melt event on CryoSat-2 elevation estimates has been previously assessed over Greenland [21]; within a $90000 \mathrm{~km}^{2}$ area around the North Greenland Eemian Ice Drilling Project (NEEM) camp (Fig. 2), an increase in surface elevation of $1.24 \pm 0.51 \mathrm{~m}$ was recorded across the period of the melt event. Our deconvolution of CryoSat-2 waveforms acquired in the same area show a decrease in radar penetration depth of $1.74 \pm 0.76 \mathrm{~m}$ between the 30-day periods before and after 11 July 2012, the date of the maximum singleday melt extent [18]. Although the change in surface elevation and penetration depth are similar, they are not equivalent as a waveform retracker is applied to the elevation measurement to reduce the impact of volume scattering, and so a lower elevation change is to be expected.

Following the formation of the new radar scattering horizon after the 2012 melt event, backscattered power increasingly shifts to the ice sheet volume year-on-year during subsequent years (Fig. 1, Fig. 2). An extreme melt event can be defined as one which produces more than $1 \mathrm{~mm}$ w.e./day of melting [38]. Between 1995 and 2015, the only melt event of such magnitude to affect the Greenland ice sheet interior was July 2012 [37]. Snowfall has since accumulated on the ice sheet surface, forming an increasingly thick new firn layer above the 2012 horizon. This change in firn structure is consistent with the evolution of backscattered power, which has returned to its pre-melt event state over the same period. Continued increases in the proportion of volume scattering since 2015 suggest that no further melting significant enough to disrupt the Ku band radar scattering horizon in the ice sheet interior has occurred within our study area. By comparing our yearly estimates of radar penetration depth to its pre-melt average (Fig. 2) we estimate that, by the end of 2017, the scattering horizon has lowered to a depth of $3.28 \pm 1.13 \mathrm{~m}$ on average, to within approximately $0.5 \mathrm{~m}$ of that recorded before July $2012(3.79 \pm 1.12 \mathrm{~m})$.

At the regional scale, the step-like reduction in the average penetration depth across the interior of the ice sheet as a result of the 2012 melt event is clearly visible (Fig. 3). By fitting a linear trend to the penetration depth time series between 2013 and 2017, we find that since the melt event the radar scattering horizon has lowered by $0.4 \mathrm{~m} / \mathrm{yr}$, on average. Assuming it continues at this rate, backscattered power from the ice sheet interior will return to near its pre-melt distribution by 2020 , provided that there are no further extreme melt events of the scale recorded in 2012. We note that the rate at which the scattering horizon lowers is not equivalent to the downward velocity of the ice lens formed in 2012, and is dependent on the firn compaction rate in addition to the surface mass balance.

\section{B. Elevation Change}

To further explore the relationship between fluctuations in penetration depth and elevation, we also examined estimates of ice sheet elevation change derived from ranges corrected using a variety of waveform retrackers (e.g. Fig. 3b). When the CFI retracker is used (Fig. 3), we observe a step-like increase in elevation of $91 \pm 17 \mathrm{~cm}$ over the summer of 2012, consistent with previous findings [21]. Although less sensitive to changes in volume scattering, we also observe a step increase of $21 \pm 9 \mathrm{~cm}$ when a TCOG retracker is applied. A step of similar magnitude is also apparent in the elevation time series corrected for fluctuations in backscattered power, which does capture the changes in volume scatter coincident with the melt event. Although both retrackers lead to elevation changes that are small by comparison to the change in penetration depth (Fig. 3a), a step is still present. However, when the penetration depth is included as an additional factor in the elevation change retrieval (6), the step is further reduced (Fig. 3b).

The degree of correlation between changes in penetration depth and surface elevation is dependent upon a number of factors, including the waveform retracker, the time period considered, and the ice sheet location. For grid cells within the dry snow zone changes in penetration depth account for, on average, $14 \%$ and $1 \%$ of the observed variance in elevations derived from the CFI and TCOG retrackers over the entire time period, respectively. In addition, a change in radar penetration depth of $1 \mathrm{~m}$ corresponds to a change of $0.21 \mathrm{~m}$ and $0.06 \mathrm{~m}$ in the retracked height derived from the CFI and TCOG algorithms on average, respectively. Overall there is higher spatial variability in the correlation between changes in height and penetration depth for the CFI retracker than for the TCOG retracker (standard deviation of the Pearson correlation coefficient, $R$, of 0.18 and 0.10 , respectively). In both cases, we find significantly higher correlation within the dry snow zone (reaching a maximum of $R=-0.70$ for CFI and $R=-0.40$ for TCOG). Within the percolation zone, we find little association between changes in penetration depth and height for both retrackers $(R=-0.05$ for CFI and $R=$ -0.01 for TCOG, on average).

The pattern of regional elevation change calculated over both time periods broadly agrees with the pattern derived from the sparse repeat airborne laser altimetry (Fig. 4). Previously identified signals of ice thinning at individual glaciers and along the western margin (e.g. [3]-[6]) are well resolved in both datasets. We find the highest rates of thinning at key marine terminating glaciers known to be in a state of dynamical imbalance (e.g. Jakobshavn Isbræ, Kangerlussuaq and Upernavik Isstrøm). Our longer 7-year survey period (2011-2017) reveals that these high rates of thinning (in excess of $2 \mathrm{~m} / \mathrm{yr}$ ) have persisted at these sites throughout the decade, in agreement with the laser altimetry. We also resolve losses resulting from seasonal melt in the ablation zone close to the ice sheet margin. We note that differences between the radar and airborne laser altimetry may arise due to the way 

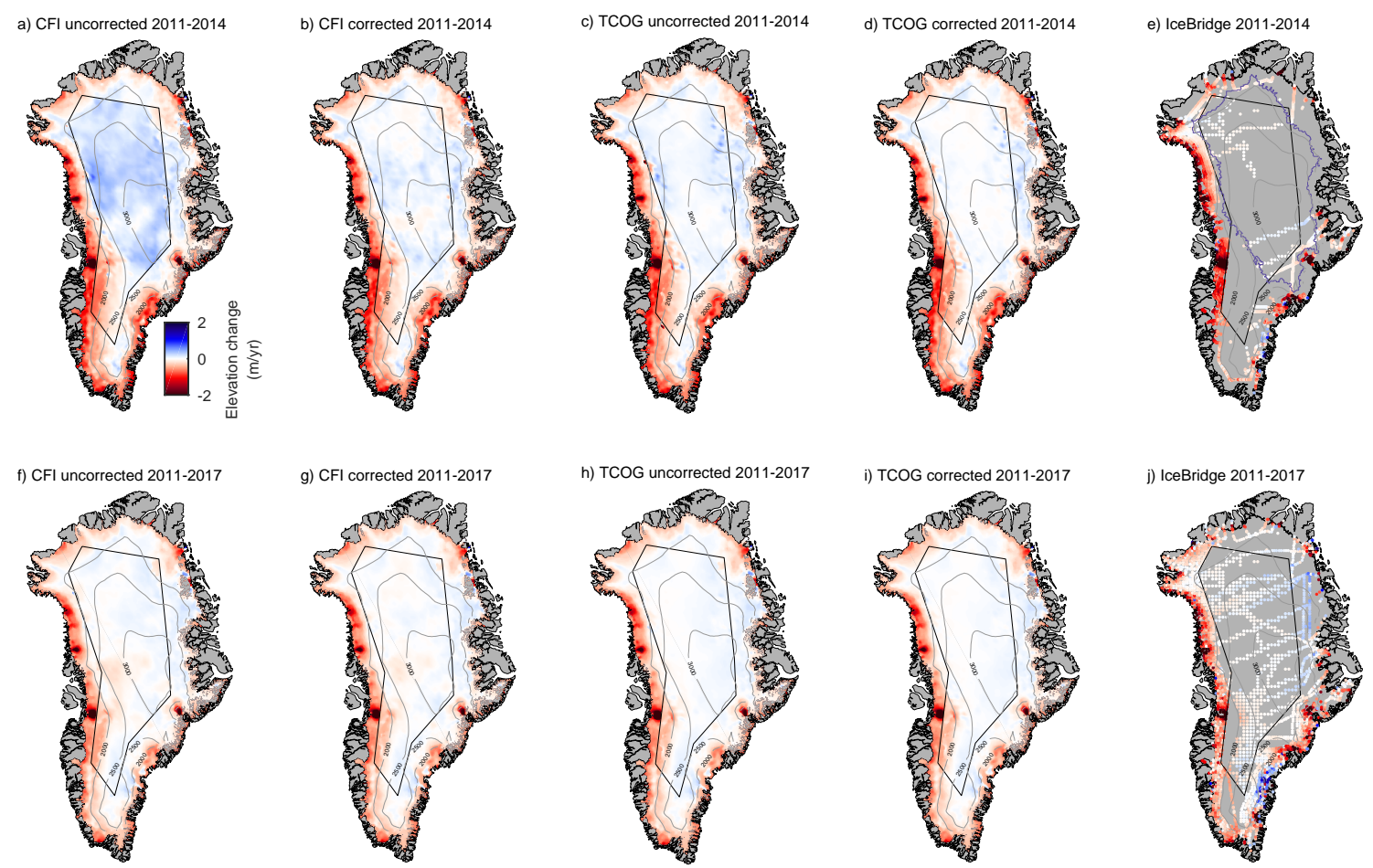

Fig. 4. Rates of surface elevation change calculated at a resolution of $5 \mathrm{~km}$ for SARIn mode (smoothed with a $25 \times 25 \mathrm{~km}$ median filter) using heights from the SARIn retracker, and at a resolution of $25 \mathrm{~km}$ for LRM (resampled to $5 \mathrm{~km}$ here using nearest neighbour interpolation for visualisation purposes) using heights calculated from the CFI and TCOG retracking algorithms. Results are shown for LRM solutions that have been both uncorrected (a, f, c, h) and corrected (b, g, d, i) for changes in radar penetration depth, and for the time periods 2011-2014 (top) and 2011-2017 (bottom). (e, j) Rates of elevation change derived from repeat IceBridge airborne laser altimetry. In each plot, the black line represents the boundary between LRM and SARIn mode acquisitions, and grey lines represent elevation contours of 2000, 2500 and $3000 \mathrm{~m}$. Also shown in (e) is the boundary of the dry snow zone (purple), as defined in McMillan et al. [4].

TABLE I

STATISTICS OF THE COMPARISON BETWEEN CRYOSAT-2 AND OPERATION ICEBRIDGE RATES OF ELEVATION CHANGE FOR THE INTERIOR OF THE GREENLAND ICE SHEET (AREAS GREATER THAN 2000 M.A.S.L.) FOR THE TIME PERIODS 2011-2014 AND 2011-2017.

\begin{tabular}{|c|c|c|c|c|c|c|}
\hline & \multicolumn{6}{|c|}{ CryoSat-2 - IceBridge elevation change statistics $(>2000 \mathrm{~m})$} \\
\hline & 2011-2014 & & & 2011-2017 & & \\
\hline & $\begin{array}{l}\text { Mean } \\
\text { difference }(\mathrm{m} / \mathrm{yr})\end{array}$ & $\begin{array}{l}\text { Standard } \\
\text { deviation }(\mathrm{m} / \mathrm{yr})\end{array}$ & $\begin{array}{l}\text { Number of } \\
\text { comparisons }\end{array}$ & $\begin{array}{l}\text { Mean } \\
\text { difference }(\mathrm{m} / \mathrm{yr})\end{array}$ & $\begin{array}{l}\text { Standard } \\
\text { deviation }(\mathrm{m} / \mathrm{yr})\end{array}$ & $\begin{array}{l}\text { Number of } \\
\text { comparisons }\end{array}$ \\
\hline \multicolumn{7}{|l|}{ CFI retracker } \\
\hline Uncorrected & 0.20 & 0.10 & 135 & 0.01 & 0.11 & 585 \\
\hline Power correction & 0.19 & 0.11 & 135 & 0.01 & 0.18 & 585 \\
\hline Penetration depth correction & 0.06 & 0.08 & 135 & 0.01 & 0.10 & 585 \\
\hline \multicolumn{7}{|l|}{ TCOG retracker } \\
\hline Uncorrected & 0.07 & 0.08 & 135 & 0.02 & 0.10 & 585 \\
\hline Power correction & 0.06 & 0.07 & 135 & 0.02 & 0.17 & 585 \\
\hline Penetration depth correction & 0.03 & 0.07 & 135 & 0.02 & 0.10 & 585 \\
\hline
\end{tabular}

in which we have constructed the reference dataset. Although averaging the IceBridge trends calculated over multiple epochs provides superior spatial coverage, particularly in the ice sheet interior, we note that this may introduce some interannual variability in the elevation rates. Therefore, we do not expect to see an exact correspondence between elevation rates measured by IceBridge and CryoSat- 2 altimetry. Over short repeat periods the laser altimetry may capture short-term changes which are smoothed out by the longer time interval used for the radar altimetry. For example, in our 2011-2017 datasets, it is possible that moderate thickening not seen in the radar altimetry but present in two flight lines in the northeast beyond the LRM boundary (Fig. 4j) is the result of short-term accumulation occurring between the laser survey dates (2013 and 2014).

Because the 2012 melt event is unique during the period of 

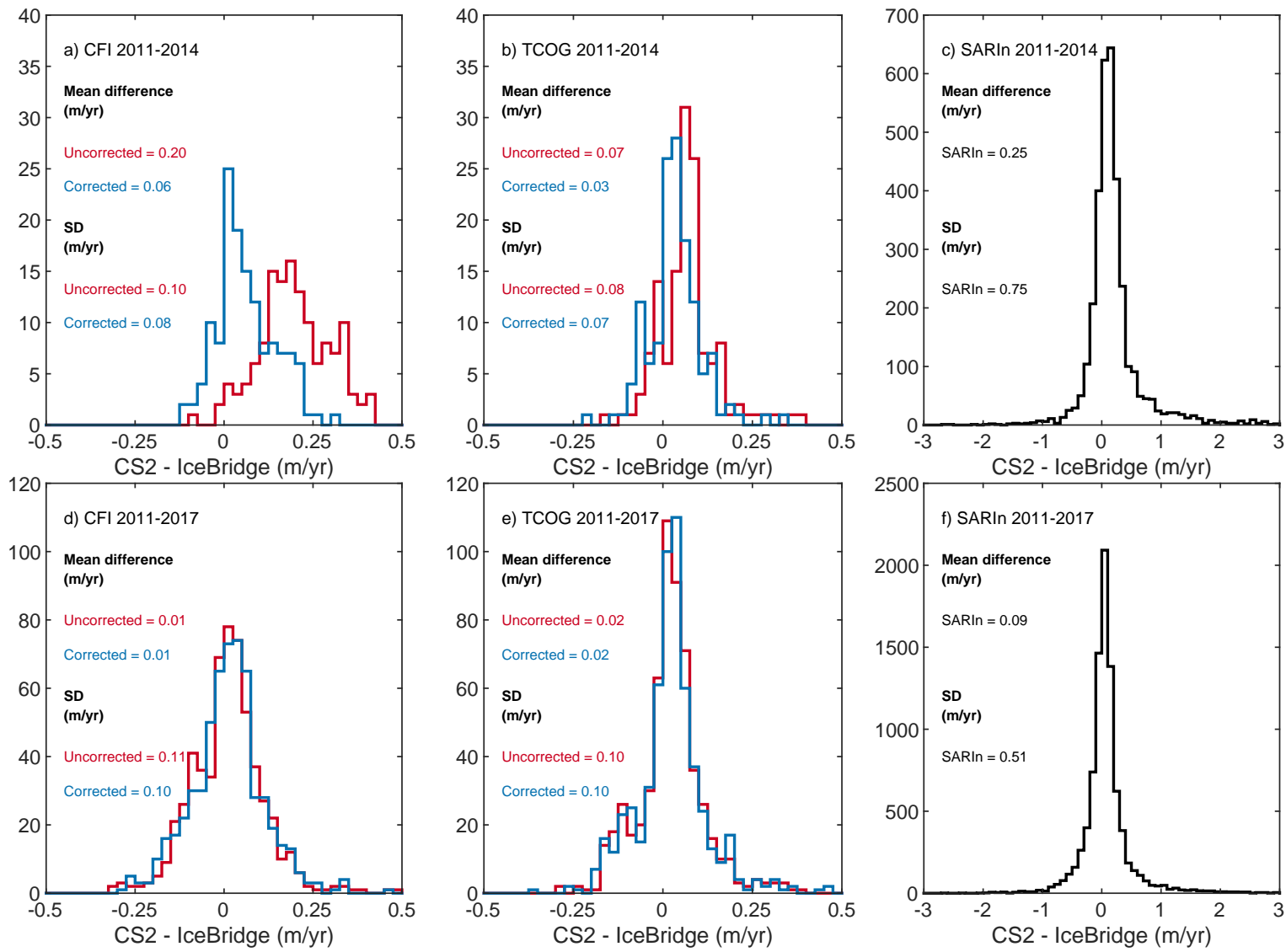

Fig. 5. Comparison of uncorrected (red) and penetration depth corrected (blue) CryoSat-2 elevation rates to Operation IceBridge airborne laser altimetry rates between (top) January 2011 and December 2014 and (bottom) January 2011 and December 2017 for (a, d) CFI retracker, (b, e) TCOG retracker in the LRM zone, and (c, f) in the SARIn zone.

the CryoSat-2 data, its effect is more pronounced on rates of elevation change that are calculated over shorter time intervals (Fig. 4). Over the full period of our survey (2011-2017), differences between regionally averaged rates of elevation change in the interior of the Greenland ice sheet are $1 \mathrm{~cm} / \mathrm{yr}$, regardless of which retracker is used (CFI or TCOG) or if a penetration depth correction is applied. In contrast, over shorter periods the 2012 melt event introduces a significant positive bias in rates of elevation change in the interior if uncorrected (Fig. 4), as has been previously observed [5], [6]. This bias is much more apparent for elevation rates calculated from the CFI retracker (Fig. 4a), which displays differences up to $42 \mathrm{~cm} / \mathrm{yr}$ relative to the rates determined from the laser altimetry. However, once changes in radar penetration depth have been accounted for using our penetration depth correction, the average elevation rate (2011-2014) within the LRM region is significantly reduced, from $14.6 \pm 2.7 \mathrm{~cm} / \mathrm{yr}$ to $2.4 \pm 2.6 \mathrm{~cm} / \mathrm{yr}$. When applying the penetration depth correction to TCOG elevation time series over the same time period, we also find the elevation rate in the interior is reduced from $3.3 \pm 1.4 \mathrm{~cm} / \mathrm{yr}$ to $-0.2 \pm 1.3 \mathrm{~cm} / \mathrm{yr}$, on average. For comparison, the average rate of elevation change computed from airborne surveys falling within the LRM zone and between 2011-2014 is $-2.1 \pm 4.2 \mathrm{~cm} / \mathrm{yr}$. Although the airborne data are sufficient to conclude that the penetration depth correction to both the CFI and TCOG elevation data is effective, their spatial distribution is too sparse to pick which of the corrected CFI and TCOG solutions is more accurate for deriving long term elevation trends.

Examining rates of elevation change within the dry snow zone in more detail, it is clear that the penetration depth correction reduces the positive bias induced by the 2012 melt event in comparison to the airborne data (Table I, Fig. 5), regardless of the retracker or whether the trends have been corrected for fluctuations in backscattered power. For the CFI algorithm, which is more sensitive to fluctuations in the radar scattering horizon, applying the retracker correction reduces the mean and standard deviation of the differences by $14 \mathrm{~cm} / \mathrm{yr}$ and $2 \mathrm{~cm} / \mathrm{yr}$, respectively, when compared to the uncorrected data. Although designed to be less influenced by such fluctuations, our penetration correction also improves elevation rates derived from the TCOG algorithm, decreasing the mean difference and standard deviation by $4 \mathrm{~cm} / \mathrm{yr}$ and $1 \mathrm{~cm} / \mathrm{yr}$, respectively. These results are comparable to an 
intercomparison to a different subset of IceBridge data over a similar time period performed in a previous study [6], which found a median difference of $1 \mathrm{~cm} / \mathrm{yr}$ and standard deviation of $32 \mathrm{~cm} / \mathrm{yr}$ when accounting for changes in the echo leading edge. Over the longer 2011-2017 survey period, both retrackers perform similarly well in all three scenarios when compared to the laser altimetry (Table I). In each case, the effect of the penetration depth correction is negligible due to the reduced effect of the melt event on elevation rates derived from longer time intervals. Over both time periods we find reasonable agreement between elevation rates derived from SARIn and laser altimetry (Fig. 5). Between 2011-2014 and 2011-2017 we calculate a mean difference and standard deviation of $25 \mathrm{~cm} / \mathrm{yr}$ and $75 \mathrm{~cm} / \mathrm{yr}$, and $9 \mathrm{~cm} / \mathrm{yr}$ and $51 \mathrm{~cm} / \mathrm{yr}$, respectively a similar order of magnitude to previous studies where an evaluation against IceBridge laser altimetry has been performed [4], [6].

\section{CONCLUSION}

By deconvolving CryoSat-2 low-resolution mode altimeter echoes, we are able to provide a record of spatio-temporal variability in $\mathrm{Ku}$ band radar backscatter and penetration depth over the interior of the Greenland ice sheet between 20112017. Within this record we identify the melt event of 2012 as an isolated disruption to the radar scattering horizon, causing a widespread shift from volume to surface scattering and reducing the radar penetration depth by $2.34 \pm 1.41 \mathrm{~m}$ on average in sectors of the ice sheet above $2000 \mathrm{~m}$ in altitude. Since then, a return to cooler atmospheric conditions [39] have allowed snowfall to accumulate across the interior of the ice sheet, and the scattering horizon has lowered, on average, to a depth of $3.28 \pm 1.13 \mathrm{~m}$ close to that seen before the melt event.

We show that changes in the penetration depth are correlated with changes in surface elevation determined from retracked radar altimeter waveform echoes, with typically 6 to $21 \mathrm{~cm}$ of elevation change occurring per metre variation in penetration depth. Accounting for the positive bias induced in elevation trends leads to improved agreement with respect to airborne laser altimetry especially when calculated over short $(<4$ year) periods. When using an empirical retracker correction based upon changes in radar penetration depth, the mean bias is reduced by up to $14 \mathrm{~cm} / \mathrm{yr}$ in the interior of the Greenland ice sheet. Over longer time periods, the correction is less important as the impact of the melt event on derived elevation trends becomes negligible. Elevation trends calculated from CryoSat-2 data processed with the TCOG retracker are much less affected by changes in penetration depth than those processed with the CFI retracker. Our study provides a physical basis for temporal variations in ice sheet elevation recorded during episodic melting events, and demonstrates an effective method to compensate for these signals through waveform deconvolution. Here our approach requires the use both Level 1 and 2 data products: in future implementing the waveform deconvolution within a Level 2 processor would allow fluctuations in penetration depth to be compensated for on an individual waveform basis.

\section{ACKNOWLEDGMENT}

This work was supported by the UK Natural Environmental Research Council (cpom300001) and the European Space Agency. T. Slater is funded through the NERC Ice Sheet Stability (iSTAR) programme and NERC grant number NE/J005681/1. T. Armitage was supported at the Jet Propulsion Laboratory, California Institute of Technology, under contract with the National Aeronautics and Space Administration. We thank ESA for the provision of CryoSat2 data (available at https://earth.esa.int/web/guest/-/cryosatproducts), and the National Snow and Ice Data Center for the provision of IceBridge airborne altimetry data (available at https://nsidc.org/icebridge/portal). We thank the editor and four anonymous reviewers for their comments, which helped improve the manuscript.

\section{REFERENCES}

[1] O. M. Johannessen, K. Khvorostovsky, M. W. Miles, and L. P. Bobylev, "Recent ice-sheet growth in the interior of Greenland," Science, vol. 310, no. 5750, pp. 1013-1016, 2005.

[2] A. Shepherd, E. R. Ivins, G. A, V. R. Barletta, M. J. Bentley, S. Bettadpur, K. H. Briggs, D. H. Bromwich, R. Forsberg, N. Galin, M. Horwath, S. Jacobs, I. Joughin, M. A. King, J. T. M. Lenaerts, J. Li, S. R. M. Ligtenberg, A. Luckman, S. B. Luthcke, M. McMillan, R. Meister, G. Milne, J. Mouginot, A. Muir, J. P. Nicolas, J. Paden, A. J. Payne, H. Pritchard, E. Rignot, H. Rott, L. S. Sørensen, T. A. Scambos, B. Scheuchl, E. J. O. Schrama, B. Smith, A. V. Sundal, J. H. van Angelen, W. J. van de Berg, M. R. van den Broeke, D. G. Vaughan, I. Velicogna, J. Wahr, P. L. Whitehouse, D. J. Wingham, D. Yi, D. Young, and H. J. Zwally, "A reconciled estimate of ice-sheet mass balance," Science, vol. 338, no. 6111, p. 1183, 2012.

[3] V. Helm, A. Humbert, and H. Miller, "Elevation and elevation change of Greenland and Antarctica derived from CryoSat-2," The Cryosphere, vol. 8, no. 4, pp. 1539-1559, 2014.

[4] M. McMillan, A. Leeson, A. Shepherd, K. Briggs, T. W. K. Armitage, A. Hogg, P. Kuipers Munneke, M. van den Broeke, B. Nol, W. J. van de Berg, S. Ligtenberg, M. Horwath, A. Groh, A. Muir, and L. Gilbert, "A high-resolution record of Greenland mass balance," Geophysical Research Letters, vol. 43, no. 13, pp. 7002-7010, 2016.

[5] J. Nilsson, A. Gardner, L. Sandberg Sørensen, and R. Forsberg, "Improved retrieval of land ice topography from CryoSat-2 data and its impact for volume-change estimation of the Greenland ice sheet," The Cryosphere, vol. 10, no. 6, pp. 2953-2969, 2016.

[6] S. B. Simonsen and L. S. Sørensen, "Implications of changing scattering properties on Greenland ice sheet volume change from CryoSat-2 altimetry," Remote Sensing of Environment, vol. 190, pp. 207-216, 2017.

[7] L. Sandberg Sørensen, S. B. Simonsen, R. Forsberg, K. Khvorostovsky, R. Meister, and M. E. Engdahl, "25 years of elevation changes of the Greenland ice sheet from ERS, Envisat, and CryoSat-2 radar altimetry," Earth and Planetary Science Letters, vol. 495, pp. 234-241, 2018.

[8] J. K. Ridley and K. C. Partington, "A model of satellite radar altimeter return from ice sheets," International Journal of Remote Sensing, vol. 9, no. 4, pp. 601-624, 1988.

[9] C. H. Davis and R. K. Moore, "A combined surface-and volumescattering model for ice-sheet radar altimetry," Journal of Glaciology, vol. 39, no. 133, pp. 675-686, 1993.

[10] R. J. Arthern, D. J. Wingham, and A. L. Ridout, "Controls on ERS altimeter measurements over ice sheets: Footprint-scale topography, backscatter fluctuations, and the dependence of microwave penetration depth on satellite orientation," Journal of Geophysical Research: Atmospheres, vol. 106, no. D24, pp. 33 471-33 484, 2001.

[11] D. J. Wingham, C. R. Francis, S. Baker, C. Bouzinac, D. Brockley, R. Cullen, P. de Chateau-Thierry, S. W. Laxon, U. Mallow, C. Mavrocordatos, L. Phalippou, G. Ratier, L. Rey, F. Rostan, P. Viau, and D. W. Wallis, "CryoSat: A mission to determine the fluctuations in Earths land and marine ice fields," Advances in Space Research, vol. 37, no. 4, pp. 841-871, 2006

[12] T. W. K. Armitage, D. J. Wingham, and A. L. Ridout, "Meteorological origin of the static crossover pattern present in low-resolution-mode CryoSat-2 data over central Antarctica," IEEE Geoscience and Remote Sensing Letters, vol. 11, no. 7, pp. 1295-1299, 2014. 
[13] C. Matzler, "Microwave permittivity of dry snow," IEEE Transactions on Geoscience and Remote Sensing, vol. 34, no. 2, pp. 573-581, 1996.

[14] C. H. Davis and H. J. Zwally, "Geographic and seasonal variations in the surface properties of the ice sheets by satellite-radar altimetry," Journal of Glaciology, vol. 39, no. 133, pp. 687-697, 1993.

[15] C. H. Davis, "A robust threshold retracking algorithm for measuring ice-sheet surface elevation change from satellite radar altimeters," IEEE Transactions on Geoscience and Remote Sensing, vol. 35, no. 4, pp. 974-979, 1997.

[16] S. V. Nghiem, D. K. Hall, T. L. Mote, M. Tedesco, M. R. Albert, K. Keegan, C. A. Shuman, N. E. DiGirolamo, and G. Neumann, "The extreme melt across the Greenland ice sheet in 2012," Geophysical Research Letters, vol. 39, no. 20, 2012.

[17] X. Fettweis, E. Hanna, C. Lang, A. Belleflamme, M. Erpicum, and H. Gallée, "Brief communication: Important role of the mid-tropospheric atmospheric circulation in the recent surface melt increase over the Greenland ice sheet," The Cryosphere, vol. 7, no. 1, pp. 241-248, 2013.

[18] M. Tedesco, X. Fettweis, T. Mote, J. Wahr, P. Alexander, J. E. Box, and B. Wouters, "Evidence and analysis of 2012 Greenland records from spaceborne observations, a regional climate model and reanalysis data," The Cryosphere, vol. 7, no. 2, pp. 615-630, 2013.

[19] K. A. Casey, C. M. Polashenski, J. Chen, and M. Tedesco, "Impact of MODIS sensor calibration updates on Greenland ice sheet surface reflectance and albedo trends," The Cryosphere, vol. 11, no. 4, pp. 17811795, 2017.

[20] T. L. Mote, "Greenland surface melt trends 19732007: Evidence of a large increase in 2007," Geophysical Research Letters, vol. 34, no. 22, 2007.

[21] J. Nilsson, P. Vallelonga, S. B. Simonsen, L. S. Sørensen, R. Forsberg, D. Dahl-Jensen, M. Hirabayashi, K. Goto-Azuma, C. S. Hvidberg, H. A. Kjaer, and K. Satow, "Greenland 2012 melt event effects on CryoSat2 radar altimetry," Geophysical Research Letters, vol. 42, no. 10, pp. 3919-3926, 2015.

[22] D. J. Wingham and D. W. Wallis, "The rough surface impulse response of a pulse-limited altimeter with an elliptical antenna pattern," IEEE Antennas and Wireless Propagation Letters, vol. 9, pp. 232-235, 2010.

[23] K. C. Partington, J. K. Ridley, C. G. Rapley, and H. J. Zwally, "Observations of the surface properties of the ice sheets by satellite radar altimetry," Journal of Glaciology, vol. 35, no. 120, pp. 267-275, 1989.

[24] C. H. Davis, "A surface and volume scattering retracking algorithm for ice sheet satellite altimetry," IEEE Transactions on Geoscience and Remote Sensing, vol. 31, no. 4, pp. 811-818, 1993.

[25] D. J. Wingham, L. Phalippou, C. Mavrocordatos, and D. Wallis, "The mean echo and echo cross product from a beamforming interferometric altimeter and their application to elevation measurement," IEEE Transactions on Geoscience and Remote Sensing, vol. 42, no. 10, pp. 23052323, 2004.

[26] G. Brown, "The average impulse response of a rough surface and its applications," IEEE Transactions on Antennas and Propagation, vol. 25, no. 1, pp. 67-74, 1977.

[27] D. W. Marquardt, "An algorithm for least-squares estimation of nonlinear parameters," Journal of the Society for Industrial and Applied Mathematics, vol. 11, no. 2, pp. 431-441, 1963.

[28] D. J. Wingham, C. G. Rapley, and H. Griffiths, "New techniques in satellite altimeter tracking systems," in 18th IGARSS Symposium, 1986, Conference Proceedings.

[29] ESA, "CryoSat-2 product handbook," 2nd October 20172012. [Online]. Available: http://emits.sso.esa.int/emits-doc/ESRIN/7158/ CryoSat-PHB-17apr2012.pdf

[30] T. Flament and F. Rémy, "Dynamic thinning of Antarctic glaciers from along-track repeat radar altimetry," Journal of Glaciology, vol. 58, no. 211, pp. 830-840, 2012.

[31] D. J. Wingham, A. J. Ridout, R. Scharroo, R. J. Arthern, and C. K. Shum, "Antarctic elevation change from 1992 to 1996," Science, vol. 282, no. 5388, pp. 456-458, 1998.

[32] C. H. Davis and A. C. Ferguson, "Elevation change of the Antarctic ice sheet, 1995-2000, from ERS-2 satellite radar altimetry," IEEE Transactions on Geoscience and Remote Sensing, vol. 42, no. 11, pp. 2437-2445, 2004.

[33] K. S. Khvorostovsky, "Merging and analysis of elevation time series over Greenland ice sheet from satellite radar altimetry," IEEE Transactions on Geoscience and Remote Sensing, vol. 50, no. 1, pp. 23-36, 2012.

[34] I. Joughin, B. E. Smith, I. M. Howat, T. Scambos, and T. Moon, "Greenland flow variability from ice-sheet-wide velocity mapping," Journal of Glaciology, vol. 56, no. 197, pp. 415-430, 2010.
[35] I. Joughin, B. Smith, I. Howat, and T. Scambos, "MEaSUREs Greenland Ice Sheet velocity map from InSAR data, version 2."

[36] M. Studinger, "Icebridge ATM L4 surface elevation rate of change, Version 1," 2014.

[37] A. A. Leeson, E. Eastoe, and X. Fettweis, "Extreme temperature events on Greenland in observations and the MAR regional climate model," The Cryosphere, vol. 12, no. 3, pp. 1091-1102, 2018.

[38] B. Franco, X. Fettweis, and M. Erpicum, "Future projections of the Greenland ice sheet energy balance driving the surface melt," The Cryosphere, vol. 7, no. 1, pp. 1-18, 2013.

[39] M. Bevis, C. Harig, S. A. Khan, A. Brown, F. J. Simons, M. Willis, X. Fettweis, M. R. van den Broeke, F. B. Madsen, E. Kendrick, D. J. Caccamise, T. van Dam, P. Knudsen, and T. Nylen, "Accelerating changes in ice mass within Greenland, and the ice sheets sensitivity to atmospheric forcing," Proceedings of the National Academy of Sciences, p. 201806562, 2019. 